\title{
XRD ANALYSIS AND ISSUES OF THE CdS AND SnO2 THIN FILMS ON A GLASS SUBSTRACT FOR PHOTOVOLTAIC APPLICATIONS.
}

\author{
Pinheiro, A. G. ${ }^{1},{ }^{3}$,; Sombra, A. S. B. ${ }^{2}$; Silva, M. A. A. ${ }^{2}$ \\ ${ }^{1}$ Tecnologia em Redes de Computadores, IFCE, Canindé, Ceará, Brazil \\ 2 Depto. de Física, UFC, Fortaleza, Ceará, Brazil \\ ${ }^{3}$ Depto. de Física, UECE-FECLESC, Quixadá, Ceará, Brazil \\ *agopin@agopin.com
}

In this work we analyze the XRD of two thin films samples, one of CdS (Space group: $\mathrm{P}_{3} \mathrm{mc}$ ) and another of $\mathrm{SnO}_{2}$ (Space Group: P42/mnm) grown on a glass substract. The CdS thin film, growth via CBD (Chemical Bath Deposition), and the difficulties found for a clear peak around 2(theta)=31.2 growth in the direction [111] of the cubic structure, according to the database International Centre for Diffraction Data (ICDD), (Inorganic Crystal Structure Database ICSD) 01-080-0019. The XRD patterns were compared with the reference codes / PDF: ICSD 01-080-0019, ICSD 29278; 75-581 PDF, 029278 ICSD; PDF 10-454 067789 ICSD and the X'Pert HighScore Plus program, so that the Miller indices of the respective diffraction peaks could be identified. The analysis results showed that the films were actually composed of CdS; all films showed cubic crystal structure with lattice parameters $\mathrm{a}=\mathrm{b}=$ approximately $\mathrm{c}=5.8110 \AA ; \alpha=\beta=\gamma=\pi / 2$. But the glass substract amorphous pattern was dominant to enhance the desired peak. The solution was to apply four baths of CdS to the glass subtract to improve the peak detection. After that we then applied the spray pirolisis using $\mathrm{SnCl}_{4}$ to the glass subtract alone, in order to produce the transparent electrode of $\mathrm{SnO}_{2}$ to XRD analysis and to the final assembly of the solar cell with the CdS over the $\mathrm{SnO}_{2}$ on the glass substract. 